\title{
A 30mV input battery-less power management system
}

\author{
Jim Hui Yap, Yan Chiew Wong \\ Micro and Nano Electronic (MiNE) research group, Centre for Telecommunication Research and Innovation (CeTRI), \\ Fakulti Kejuruteraan Elektronik dan Kejuruteraan Komputer (FKEKK), Universiti Teknikal Malaysia Melaka, Hang \\ Tuah Jaya, 76100 Durian Tunggal, Melaka, Malaysia
}

\begin{tabular}{l} 
Article Info \\
\hline Article history: \\
Received Mar 29, 2019 \\
Revised Apr 24, 2019 \\
Accepted Jun 30, 2019 \\
\hline
\end{tabular}

Keywords:

Battery-less power management CMOS voltage booster Dynamic closed loop power management RF Rectifier Thermoelectric energy harvesting

\begin{abstract}
This paper presents a fully-integrated on chip battery-less power management system through energy harvesting circuit developed in a $130 \mathrm{~nm}$ CMOS process. A $30 \mathrm{mV}$ input voltage from a TEG is able to be boosted by the proposed Complementary Metal-Oxide-Semiconductor (CMOS) voltage booster and a dynamic closed loop power management to a regulated $1.2 \mathrm{~V}$. Waste body heat is harvested through Thermoelectric energy harvesting to power up low power devices such as Wireless Body Area Network. A significant finding where 1 Degree Celsius thermal difference produces a minimum $30 \mathrm{mV}$ is able to be boosted to $1.2 \mathrm{~V}$. Discontinuous Conduction Mode (DCM) digital control oscillator is the key component for the gate control of the proposed voltage booster. Radio Frequency (RF) rectifier is utilized to act as a start-up mechanism for voltage booster and power up the low voltage closed loop power management circuit. The digitally control oscillator and comparator are able to operate at low voltage $600 \mathrm{mV}$ which are powered up by a RF rectifier, and thus to kick-start the voltage booster.
\end{abstract}

Copyright $\odot 2019$ Institute of Advanced Engineering and Science. All rights reserved.

\section{Corresponding Author:}

Yan Chiew Wong,

Micro and Nano Electronic (MiNE) research group,

Centre for Telecommunication Research and Innovation (CeTRI),

Fakulti Kejuruteraan Elektronik dan Kejuruteraan Komputer,

Universiti Teknikal Malaysia Melaka,

Hang Tuah Jaya, 76100 Durian Tunggal, Melaka, Malaysia.

Email: ycwong@utem.edu.my

\section{INTRODUCTION}

Energy harvesting topic has been widely discussed as it has become a potential alternative way to replace conventional battery. This is due to the demand of low power, small size and maintanence free operation of electronic devices has been increased. Wireless Body Area Network (WBAN) is one of the applications that expected to operate for long durations but energy supply becomes a severe bottleneck and much effort has been spent on the efficient use of battery energy. A bulky battery is not desirable as the size making the node unwearable. While a small battery needs a frequent charging and replacement which reduce the wearable compliance. Another example is the pacemaker. One of the main problems about pacemakers is their batteries. As the capacity of the batteries is limited, they limit the lifetime of pacemakers [1]. In addition, implantable medical devices and stock tracking devices face a difficulty to do placement of battery beneath the body as the leakage of mercury of the battery has raise to health issue. A battery is not recommended to be placed inside the human body as it may contact with blood (such as $\mathrm{pH}$ sensor) [2].

Thermoelctric energy harvesting field has become one of the great interests recently. Thermoelectric Generator (TEGs) is a solid state device converts the temperature gradient into electrical energy. A thermoelectric generator consists of an array of pairs of semiconductor materials connected electrically in series and thermally in parallel [3]. TEG works on the principle of the Seebeck effect, when the junctions formed by joining two dissimilar current carrying conductors are maintained at different temperatures, an 
electro motive force (EMF) is generated in the circuit. The two dissimilar current carrying conductors are formed out of $\mathrm{n}$ and p-type semiconductor materials [4]. TEG utilizes heat flow across a temperature gradient to power an electric load through the external circuit [5]. When the open circuit voltage is proportional to temperature gradient, the constant of proportionality is called Seebeck coefficient [6]. Therefore, recovering from the waste heat energy like body heat to electrical energy is one of the solutions to replace batteries. The Fraunhofer scientists believe that future medical sensors may be able to draw the power they need from the warmth of the human body, with the data transmitted wirelessly to a central monitoring station [7]. In ambient environments, where the thermal difference is $1-2 \mathrm{~K}$, TEG generates several micro watts and tens of $\mathrm{mV}$ to the boost converter [8]. A thermoelectric energy generator is able to generate an output voltage of $40 \mathrm{mV}$ with a thermal gradient of $6^{\circ} \mathrm{K}$ [9]. It is a challenging task to convert such a low voltage to a DC voltage in order to power current electronic circuitry [10]. In this paper, thermal energy harvesting circuit is mainly discussed. Body heat is converted into useful electrical energy via some of the key circuitries that forms the battery-less power management system. The innovations in CMOS technology and smart circuit design have led into an era of ultra-low power systems which in-turn enabled the batteryless systems [11]. Voltage booster is the highlighted circuitry as it plays a role to boost millivolts from output of TEG to a certain desire voltage.The power management system is completed with voltage kick-starter from RF rectifier, load regulation circuitry from low dropout voltage regulator, and power on reset. To design a boost converter with self-start-up at low input voltage, designers need to trade off the choice of circuit topology, external component and CMOS process [12].

\section{RESEARCH METHOD}

Two different sizes of commercial thermoelectric generator modules TEG 1 and TEG 2 as shown in Figure 1 have been compared. The characterization has been performed by applying temperature difference between hot and cold side of module and measuring the output open circuit voltage. The data of the behaviour of TEG towards temperature difference which is collected through a simple thermoelectric generator experiment is presented in Table 1.

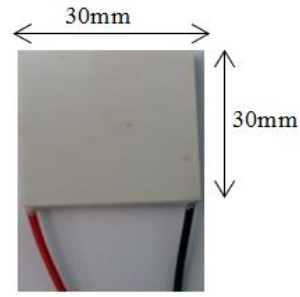

(a)

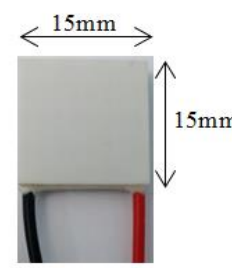

(b)

Figure 1. Measurement of, (a) TEG $1\left(30 \mathrm{~mm}^{2}\right)$, (b) TEG2 $\left(15 \mathrm{~mm}^{2}\right)$

Table 1. Behaviour of TEG towards temperature difference

\begin{tabular}{cccc}
\hline \multicolumn{4}{c}{ TEG 1} \\
\hline T1 $\left({ }^{\circ} \mathrm{C}\right)$ & $\mathrm{T} 1\left(^{\circ} \mathrm{C}\right)$ & $\mathrm{T} 1\left({ }^{\circ} \mathrm{C}\right)$ & $\mathrm{T} 1\left(^{\circ} \mathrm{C}\right)$ \\
27.4 & 27.4 & 27.4 & 27.4 \\
26.2 & 26.2 & 26.2 & 26.2 \\
24 & 24 & 24 & 24 \\
25.6 & 25.6 & 25.6 & 25.6 \\
25.7 & 25.7 & 25.7 & 25.7 \\
25.2 & 25.2 & 25.2 & 25.2 \\
28 & 40 & $12^{\circ} \mathrm{C}$ & 259 \\
\hline
\end{tabular}

\begin{tabular}{cccc}
\hline \multicolumn{4}{c}{ TEG 2 } \\
\hline $\mathrm{T} 1\left({ }^{\circ} \mathrm{C}\right)$ & $\mathrm{T} 2\left({ }^{\circ} \mathrm{C}\right)$ & $\Delta \mathrm{T}\left({ }^{\circ} \mathrm{C}\right)$ & Vout $(\mathrm{mV})$ \\
30 & 31 & $1^{\circ} \mathrm{C}$ & 3 \\
27 & 29 & $2^{\circ} \mathrm{C}$ & 10 \\
27.4 & 33.4 & $4^{\circ} \mathrm{C}$ & 14 \\
25 & 31 & $6^{\circ} \mathrm{C}$ & 23 \\
31 & 39 & $8^{\circ} \mathrm{C}$ & 33 \\
38 & 48 & $10^{\circ} \mathrm{C}$ & 52 \\
38 & 51 & $12^{\circ} \mathrm{C}$ & 59 \\
\hline
\end{tabular}

The main circuit blocks to form a battery-less power management system is discussed in detail in section 3. Figure 2 shows the block diagram of proposed energy harvesting circuitry. The challenging part in developing and designing analog integrated circuit is by defining its key parameters such as the transistor's width and length. In order to ensure the transistor is operating in an optimize region, parametric study and sizing process have to be carefully defined to avoid mismatching. Study on [13] to [14] to make sure the performance of measurement is good. 


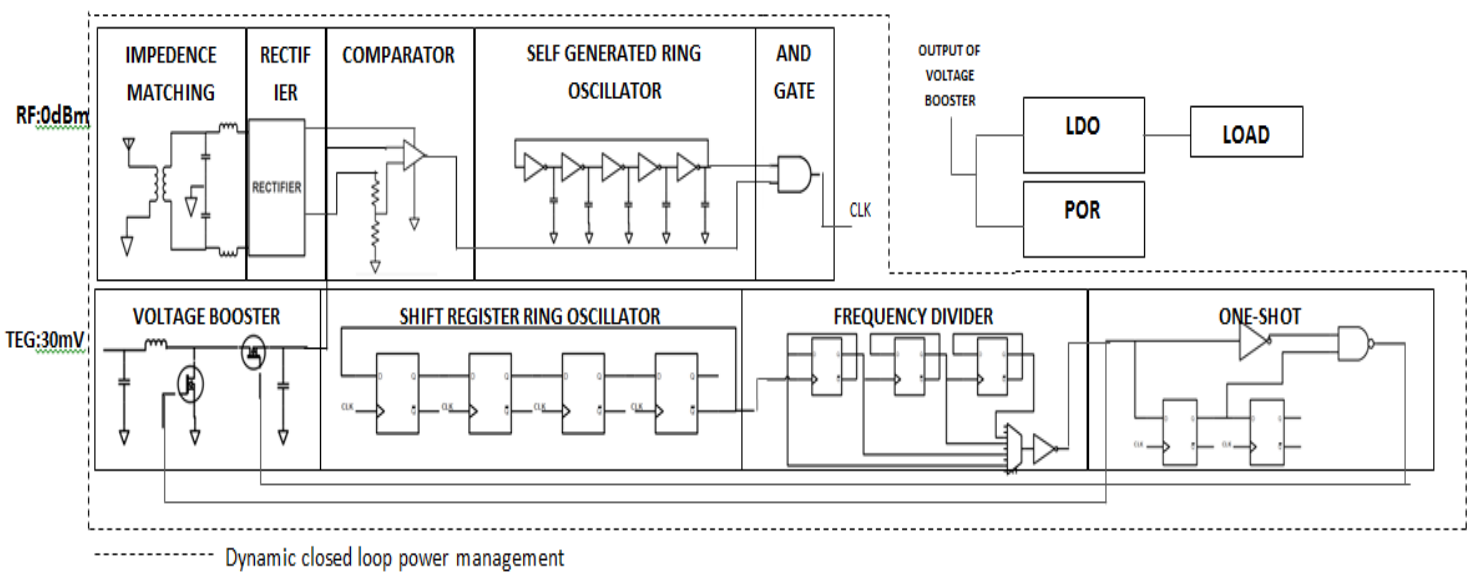

Figure 2. Power management system

\section{RESULTS AND ANALYSIS}

As expected, when the temperature difference increases, the open circuit output voltage of TEG increases. Even though the temperature difference is the same, the surface area is the key that affecting the amount of output voltage produced. From Figure 3, it shows that TEG 1 has produced higher output voltage compared to TEG 2 in the same temperature gradient.

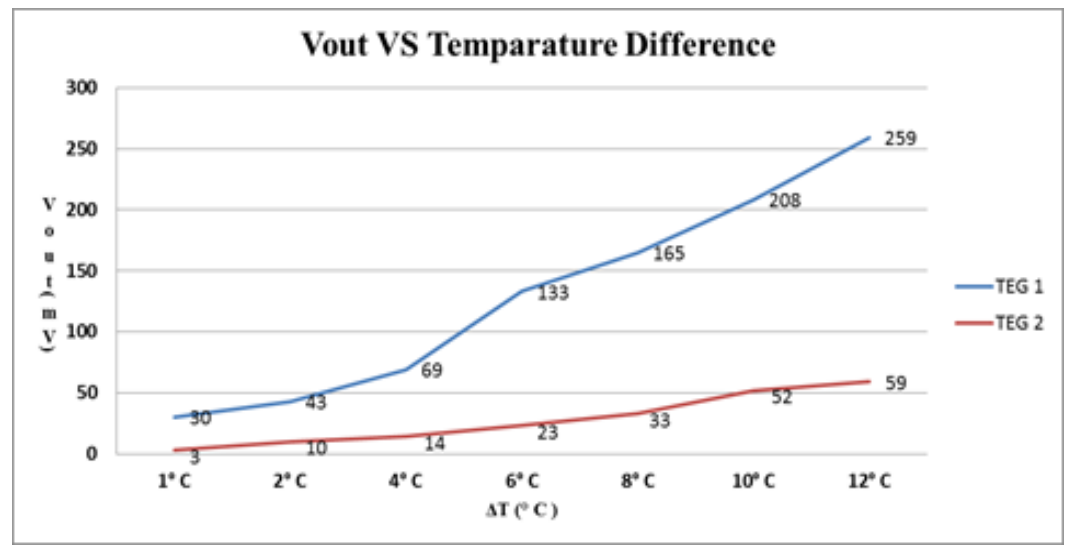

Figure 3. Comparisons of TEG 1 and TEG 2 towards temperature difference

\subsection{Voltage booster}

Voltage booster is a DC-DC converter to step up small signal DC to an output DC signal which is greater than input signal. A conventional power switch based voltage booster creates higher static and dynamic power losses of the switches which cannot be neglected. By replacing power switches with diode is another way but using diode at high side switch causes a high forward voltage drop. MOSFETs are good alternative components to replace power switches and diode in the conventional voltage booster. In order to minimize the conduction loss, very large size of NMOS and PMOS switches are required and external inductor with small DCR should be chosen [15]. This can reduce the power losses as well as the size consumption in a chip. Voltage booster operates in one of the two modes: continuous conduction mode (CCM) or discontinuous conduction mode (DCM) [16]. The limitation of the CCM is that the inductor current can flow reverse way if the load is small. While in DCM, the inductor current is prevented to flow backward which it minimizes the switching loss.

The architecture presented in the paper is inductor based voltage booster. In [17], the primary converter provides a stable output voltage of about1.2 V achieved by output node hysteresis PFM control. However, the system does not have any power management functionality. The proposed inductor based voltage booster in Figure 4 operates well with a minimum $30 \mathrm{mV}$ from the output voltage of TEG with the operation of DCM. The DCM is more efficient than the CCM as the PMOS turns off before the current flows 
negative. The discontinuous conduction mode (DCM) operation is preferred because it allows the use of small inductors where this can reduce the area consumption of power management unit in portable devices [18]. In DCM, energy is stored in the inductor when switch is closed and all energy is transferred to load when switch is opened. The voltage booster is able to boost $30 \mathrm{mV}$ to $1.2715 \mathrm{~V}$ with current drawn $2.1193 \mathrm{uA}$ under $600 \mathrm{k} \Omega$ load condition. Ideal gate control pulse for inductor based converter as shown in Figure 5 . Figure 6 is transient response of voltage booster.

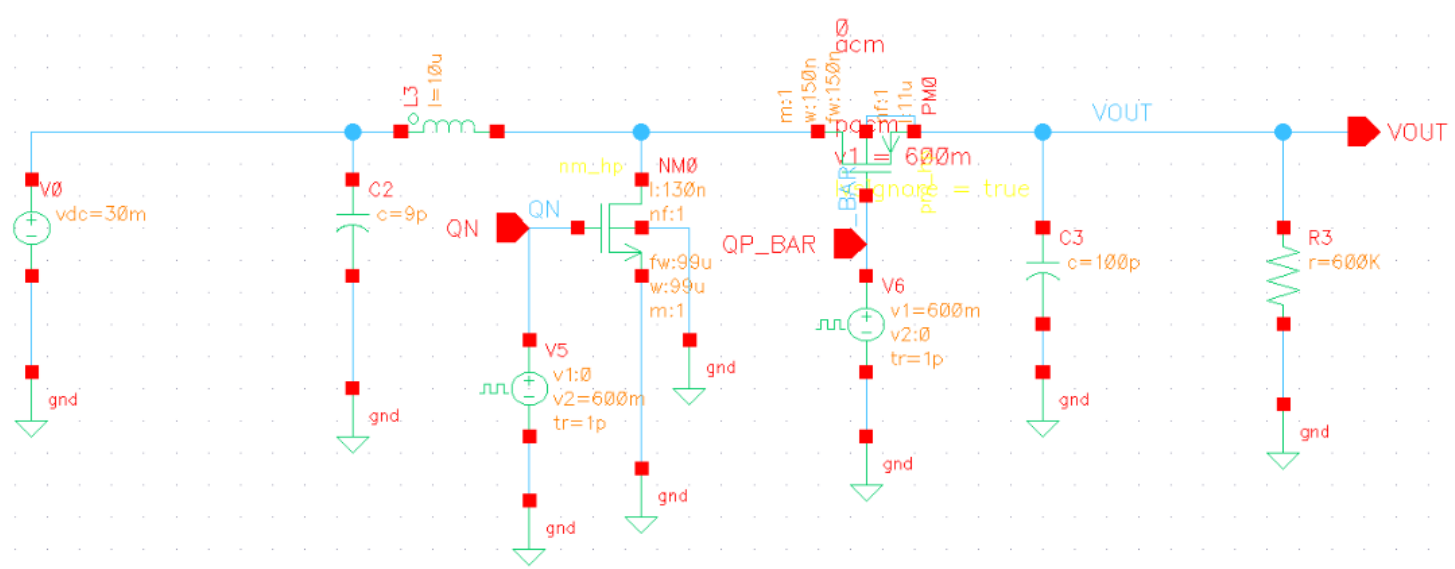

Figure 4. Inductor based voltage booster

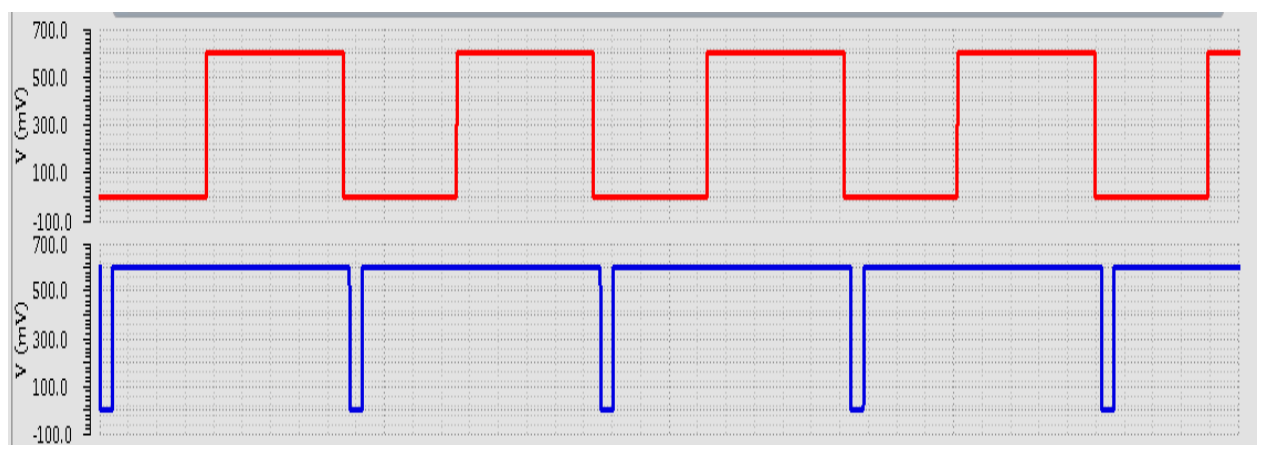

Figure 5. Ideal gate control pulse for inductor based converter

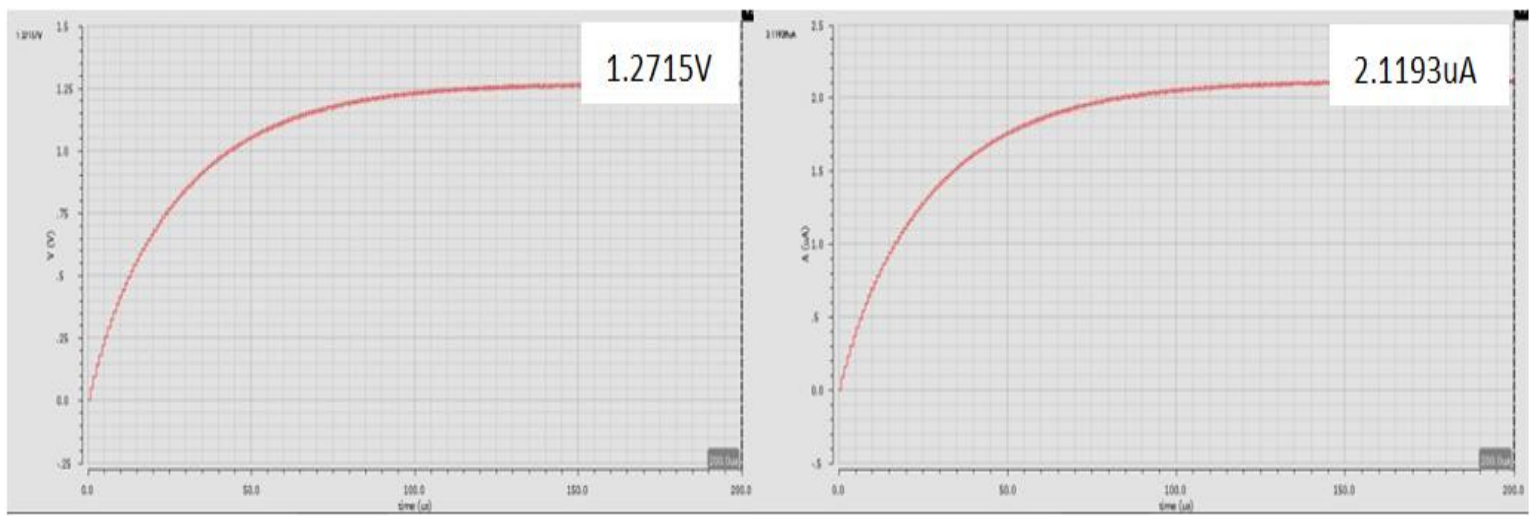

Figure 6. Transient response of voltage booster

\subsection{Digitally control oscillator}

A basic control circuitry which consists of pulse signal with a fix frequency and duty cycle is needed to drive the switches. The precise timing of turning on and off the switches is critical for high 
conversion efficiency [19]. In [20], the control circuitry is all digital and with the efficient Zero Current Switching (ZCS) circuit that supports a wide dynamic range and fine tuning of delay stages for zero current switching using only 3-bit design. The advantage of this approach is where the detection of ZCS point is evaluated using a simple D-FF where VD level state is detected after the PMOS is turned off [16]. In [21], the voltage booster is integrated with the digitally control circuit. The control circuit consists of power FET, voltage supervisor, voltage divider, oscillator, frequency control, one shot, VDD filter, and zero compare block. Example in [22], the designer utilize the Maximum Power Point Tracking and ZCS schemes to improve the efficiency of converter.

The proposed digitally control oscillator consists of five sub-blocks which are self-generated ring oscillator, clock generator, shifted register ring oscillator, frequency divider and one shot. The clock is enabled when the signal from comparator transits to high. The shifted register ring oscillator consists of four D flip-flop to generate more than $50 \%$ duty cycle square wave. This shifted square wave is then entering the frequency divider. Frequency divider is used to control the wide frequency of the input pulse from the shifted register ring oscillator. The one shot circuit sets the on time of the switching of PMOS. Figure 7 shows the block diagram of digitally control oscillator. This digitally control oscillator produces $1.136 \mathrm{MHz}$ of pulse to the gate of PMOS and NMOS for inductor based converter. As shown in schematic, the output of frequency divider enters NMOS gate while the output of one shot enters PMOS gate.

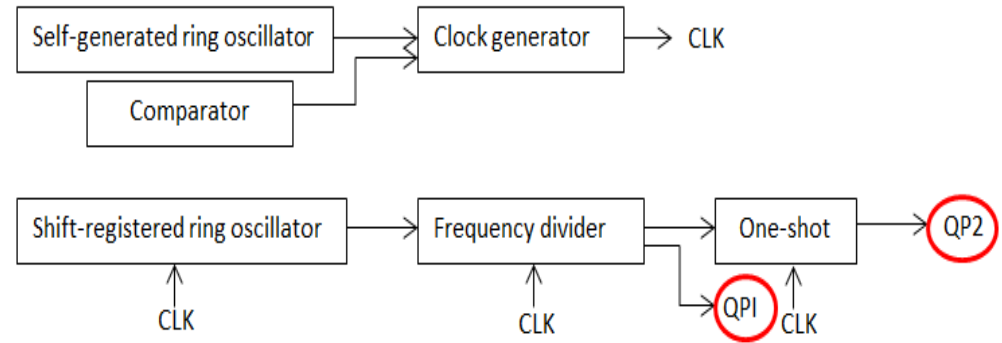

Figure 7. Digitally control oscillator

Figure 8 shows the transient result of digitally control oscillator. The red colour square waveform is produced from the frequency divider. While the blue colour square waveform is produced from one shot block. The magnitude of the gate pulse is obtained as expected which is $600 \mathrm{mV}$.

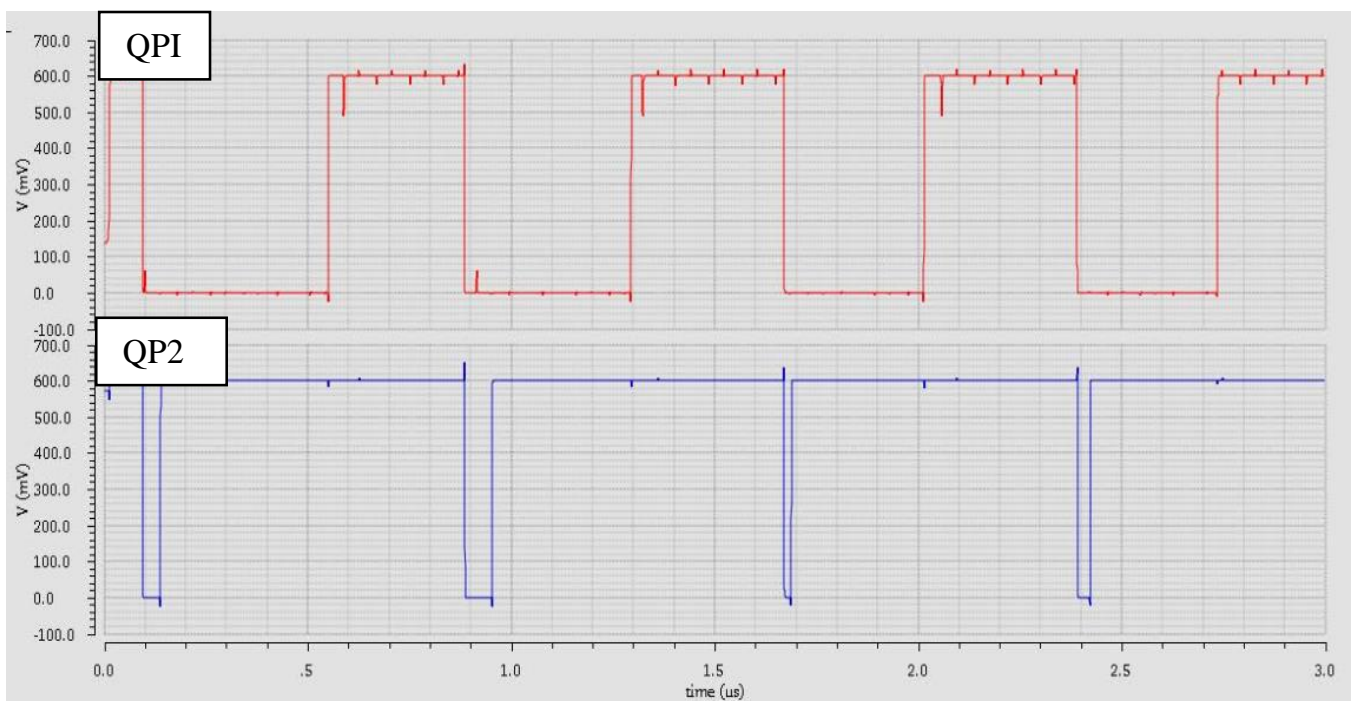

Figure 8. Transient response of digitally control oscillator

\subsection{Low voltage comparator}

The comparator is a low voltage comparator as it is able to operate at $600 \mathrm{mV}$. It is an essential block in the proposed dynamic closed loop power management as it regulates the output of voltage booster at 
certain level. All circuits are idle until the comparator activates the on-chip clock. If the output voltage of the converter drops or rises across the reference voltage, the comparator will send an active signal to an AND gate to do a comparison with self-generated pulse before it enters the clock generator to power on the rest of the digital logic circuits. Figure 9 shows the block diagram of the comparator.

Figure 10 shows the transient response of comparator with voltage divider. An ideal pulse switching has been used to model the output voltage of voltage booster. Blue colour line is the reference voltage produced by the voltage divider while the red colour line is the response of comparator. From the graph, it shows that when the output voltage of voltage booster drops below the reference voltage, the comparator transits high and vice versa.

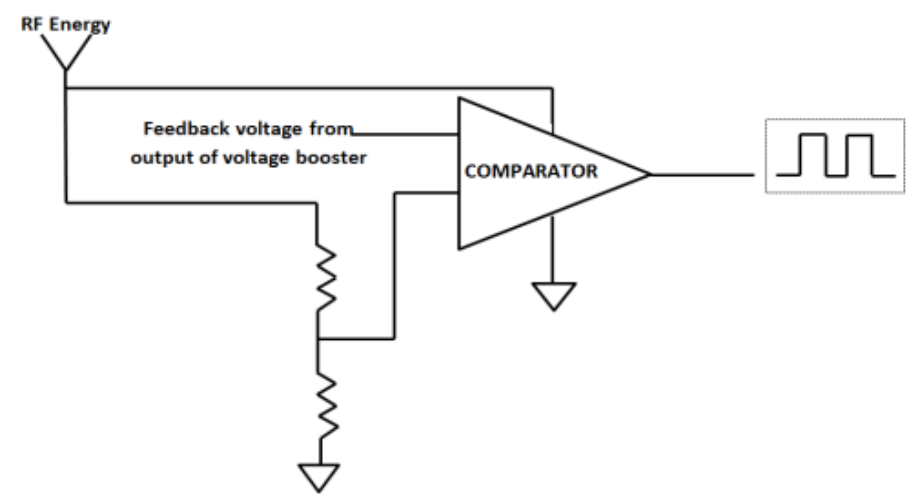

Figure 9. Comparator

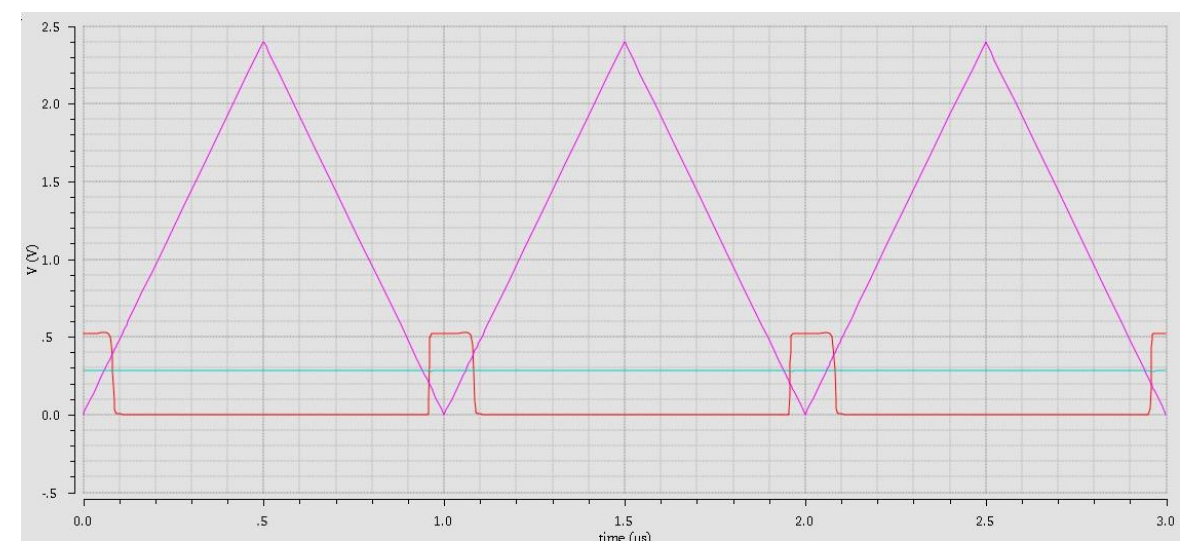

Figure 10. Transient response of comparator

\section{4. $\mathrm{RF}$ rectifier}

In the previous research, the start-up solution for voltage booster is through a pre-charge load capacitor which has been implemented in [21]. The disadvantage of using a storage element is that converter can be disabled for long periods of time. One of the major factors limiting the electrical startup is the threshold voltage of MOSFETs [23]. Thus, in this work, the RF rectifier has been used to kick start the voltage booster. From [24] and [25], it is known that diferent topologies affect its sensitivity and efficiency especially for a better energy harvesting system. In this paper, the rectifier operated at $2.45 \mathrm{GHz}$ with incident $\mathrm{RF}$ power at $0 \mathrm{dbm}$. The cross-coupled rectifier is used to have a better threshold voltage reduction as compared to the conventional rectifier. An L-matching circuit is constructed to support fully differential RF input. The entire RF rectifier is an on-chip component except the balun component. Figure 11 shows the diagram of RF rectifier with ideal balun. The balun is the only off chip component in the RF rectifier. The balun is used to create a fully differential RF signal before entering the matching circuit.

In Figure 12, the AC source is able to be converted into DC voltage for 5 stages rectifier. With the incident RF power of $0 \mathrm{dBm}$, the output voltage reaches steady state response at 8 micro second with 3.6519V with no load condition. 


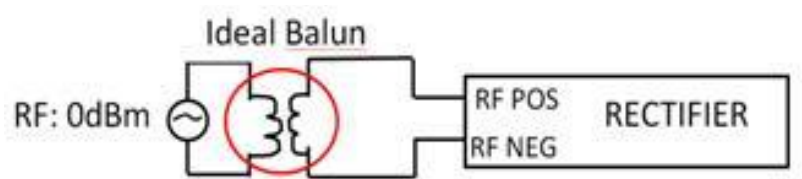

(a)

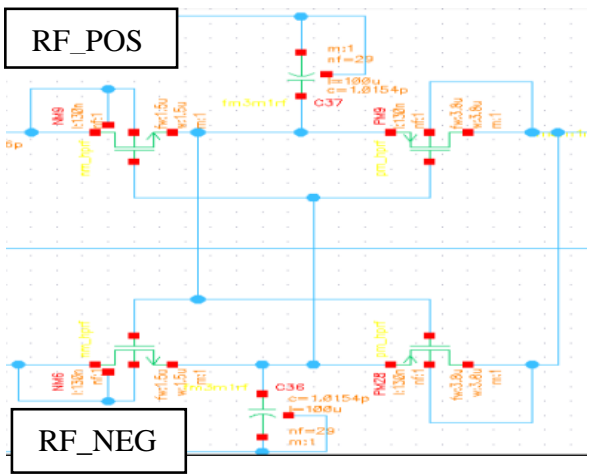

(b)

Figure 11. RF rectifier, (a) RF rectifier with ideal balun, (b) single stage rectifier

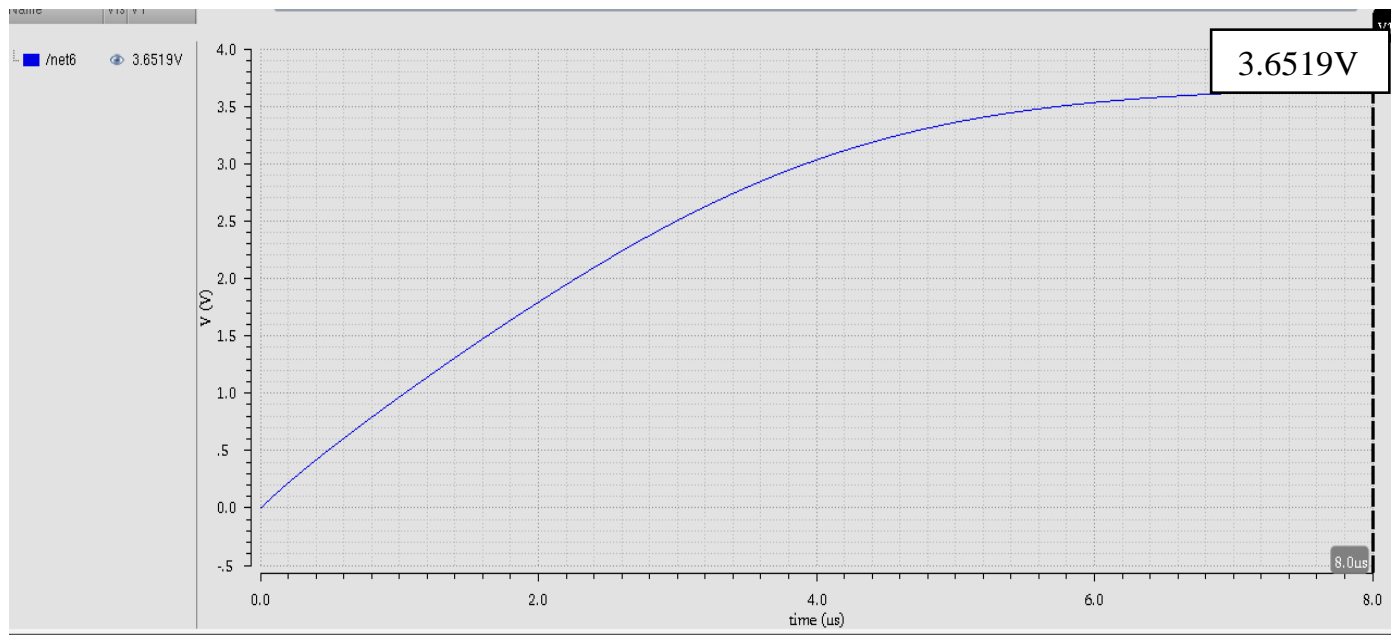

Figure 12. Transient response of rectifier

\subsection{Dynamic closed loop power management}

The design of the dynamic closed loop power management in this work is the integration of rectifier, digitally control oscillator, comparator, voltage reference and inductor based voltage booster. By referring to Figure 2, it shows the integrated circuit of dynamic closed loop power management. The dynamic closed loop power management starts to operate when there is sufficient power from RF energy for digitally control oscillator and comparator. The entire dynamic closed loop power management is a feedback loop between the output voltages. The comparator transits to high when the output voltage of voltage booster is below $1.2 \mathrm{~V}$. Once the output of voltage booster reaches $1.2 \mathrm{~V}$, it triggers the comparator to disable the digitally control oscillator.

The response of the dynamic closed loop power management is shown in Figure 13. The system takes $110 \mathrm{us}$ for start-up and start to stabilize at $1.2 \mathrm{~V}$ after $110 \mathrm{us}$. While when the output voltage drops to $1.15 \mathrm{~V}$, the voltage booster starts to charge up again. 


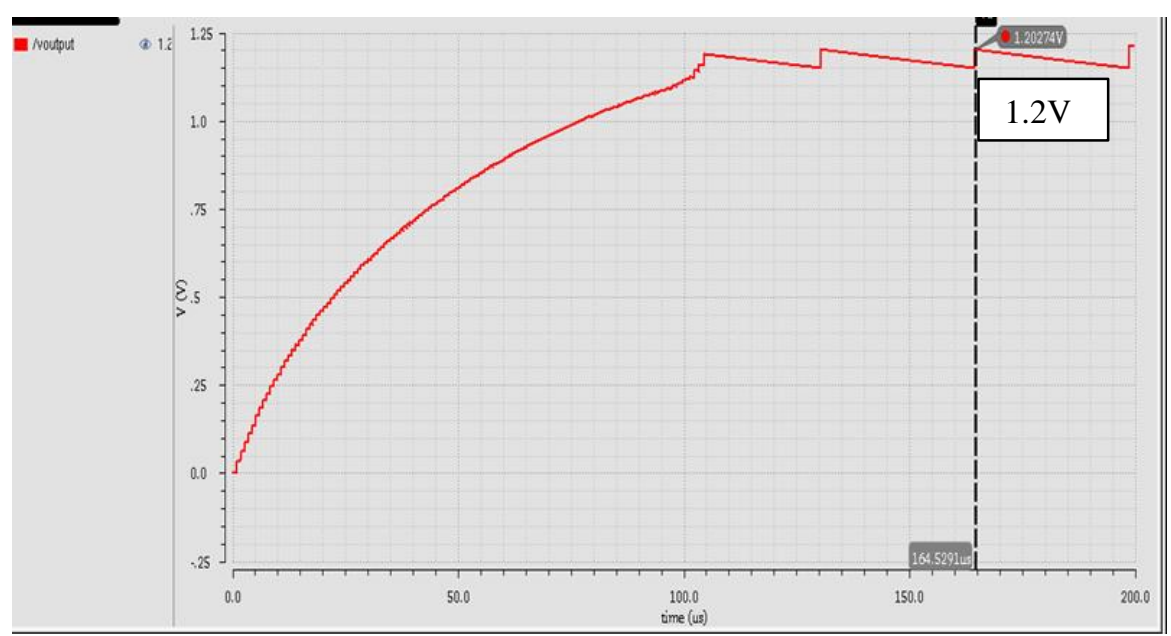

Figure 13. Regulated output voltage from dynamic closed loop power management

\subsection{Low dropout voltage regulator}

An ultra-low power CMOS Low-dropout voltage regulator is deployed to regulate the given output voltage to avoid the potentially damaging over discharge of the circuit. This LDO comprises a bandgap reference, error amplifier, a feedback-voltage divider, and a pass device. Figure 14 shows the schematic design of LDO. In Figure 15, the LDO manage to regulate $1.2 \mathrm{~V}$ when sweep with input supply from $1.2 \mathrm{~V}$ to $2.5 \mathrm{~V}$.

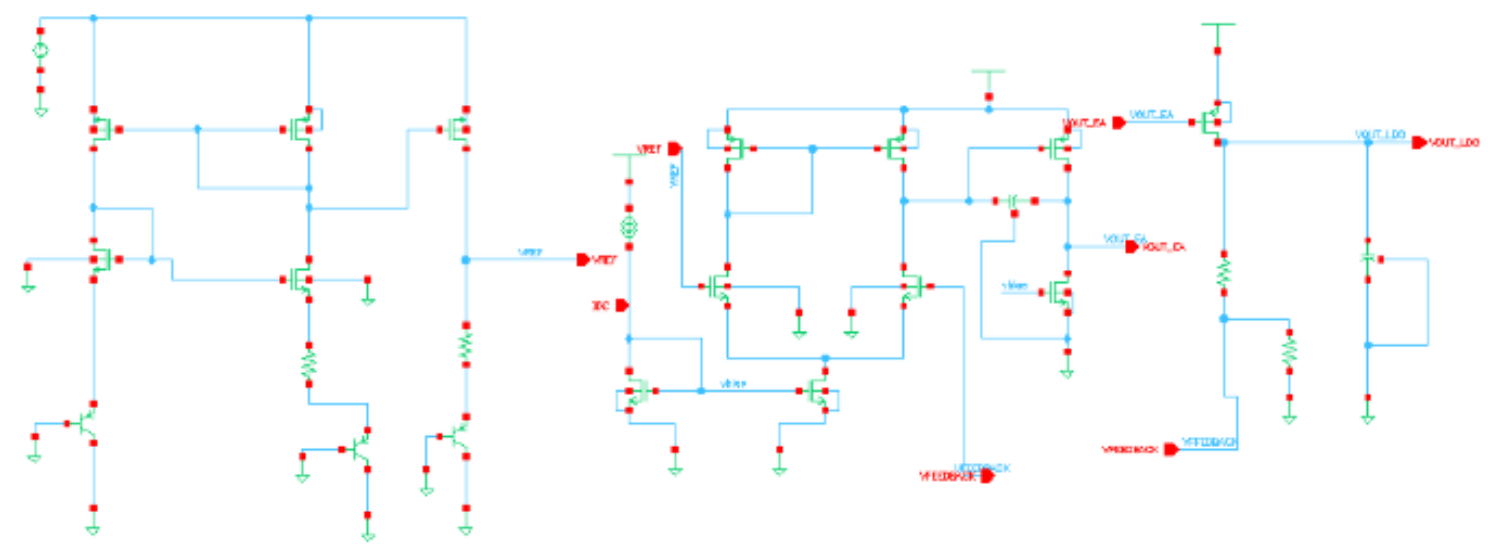

Figure 14. LDO

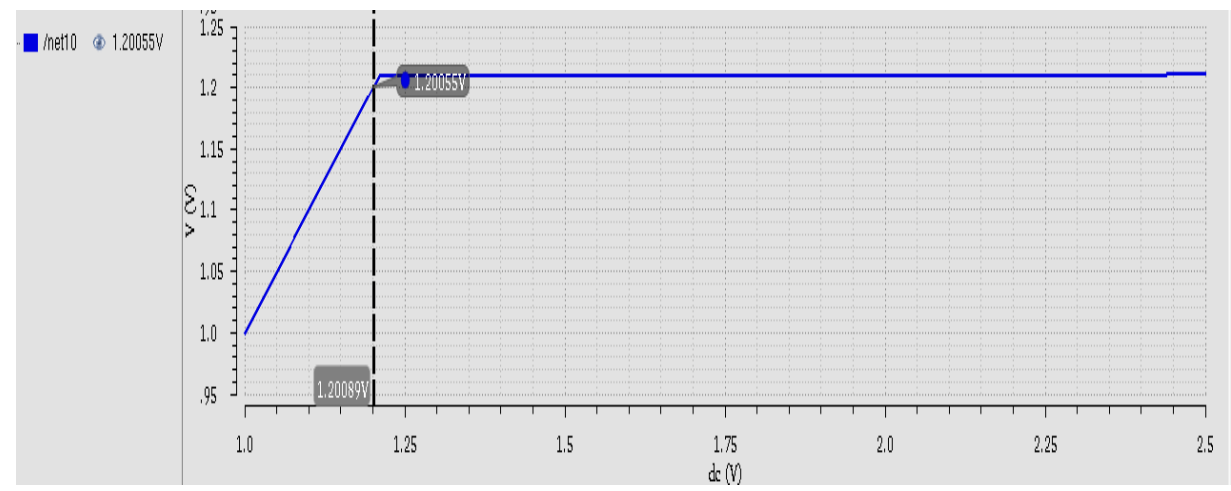

Figure 15. DC analysis 


\subsection{Power on reset}

A low voltage Power on Reset (PoR) has been developed in this work which can operate at 1.2V. PoR generates a reset pulse signal when it detects a power down trigger in the system until input voltage is stabilized. Figure 16 shows the schematic of PoR. Figure 17 illustrates the behaviour of PoR when there is power down in the system, the PoR is activated to high to reboot again the system. The power on reset is off when the input voltage reaches stable state.
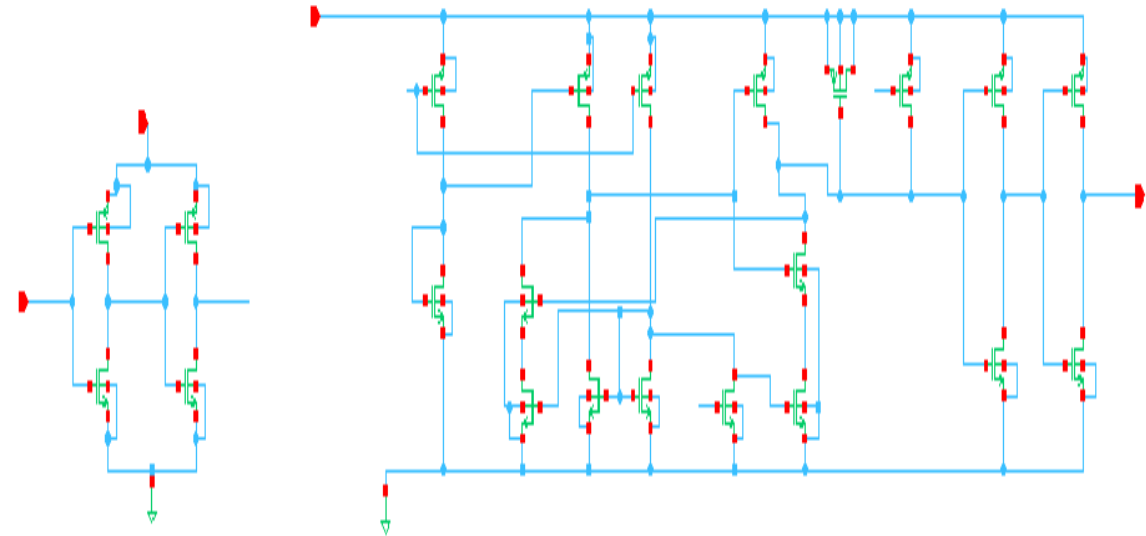

Figure 16. PoR

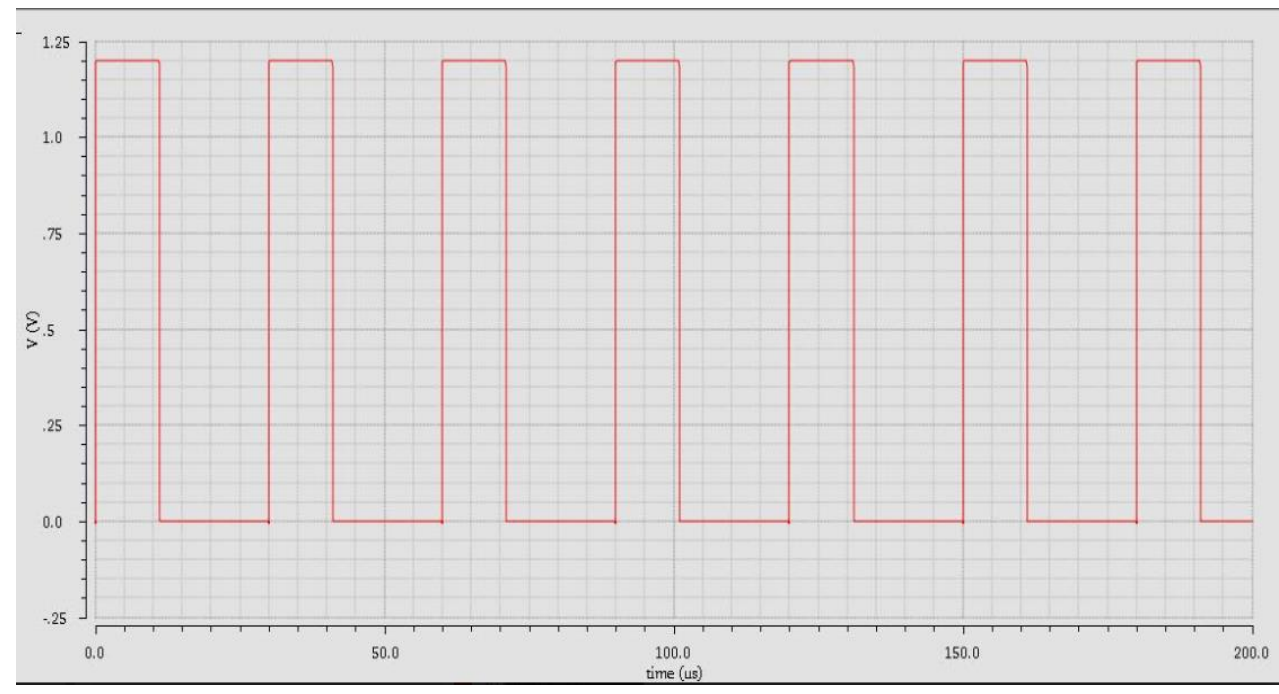

Figure 17. Transient response of PoR

\subsection{Layout of battery-less power management system}

Figure 18 shows the entire layout of battery-less power management system which includes of rectifier, voltage booster, digitally control oscillator, comparator, voltage reference, LDO and PoR. The area size of this integrated layout is $1.005928 \mathrm{~mm}^{2}$. 


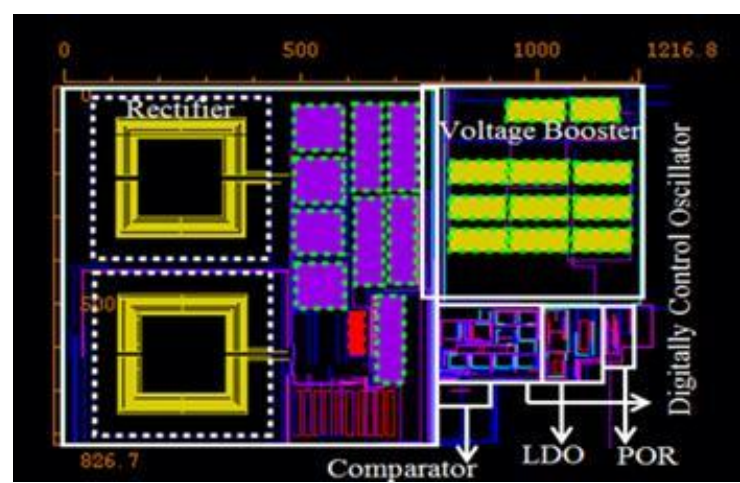

Figure 18. Layout of battery-less power management system

\section{CONCLUSION}

A significant finding in this work is where one degree Celsius temperature difference between body heat and ambient temperature is able to provide $30 \mathrm{mV}$. The battery-less power management system is able to produce a regulated $1.2 \mathrm{~V}$ from $30 \mathrm{mV}$ harvested energy from TEG by having a dynamic closed loop power management system. The optimum frequency of the pulse to control the switching period in inductor based voltage booster is in a range of $666.67 \mathrm{kHz}$ to $1.136 \mathrm{MHz}$ with a duty cycle of $50 \%$. Instead of using external electrical start-up, RF rectifier is sufficient to power up the circuitry in dynamic closed loop power management. This work demonstrates feasibility of self-powered power management system by utilizing thermal energy and RF energy to obtain a stable $1.2 \mathrm{~V}$ from $30 \mathrm{mV}$ harvested from ambient environment.

\section{ACKNOWLEDGEMENTS}

The authors acknowledge the technical and financial support by Universiti Teknikal Malaysia Melaka (UTeM) and Ministry of Science, Technology and Innovation Malaysia's grant no. 01-01-14-SF0133//L00029.

\section{REFERENCES}

[1] M. Ashraf and N. Masoumi, "A Thermal Energy Harvesting Power Supply with an Internal Startup Circuit for Pacemakers,"in IEEE Transactions on Very Large Scale Integration (VLSI) Systems, vol. 24, no. 1, pp. 26-37, Jan 2016.

[2] M. Ashraf and N. Masoumi, "A Fully-Integrated Power Supply Design for Wireless Implantable BiosensorsWireless Implantable Biosensors," The 22nd Iranian Conference on Electrical Engineering (ICEE 2014), pp. 193-196, 2014.

[3] C. Veri, M. Pasca, S. D'Amico, L. Francioso, C. De Pascali and P. Siciliano, "A flexible thermoelectric generator with a fully electrical, low startup voltage and high efficiency DC-DC converter," 2015 6th International Workshop on Advances in Sensors and Interfaces (IWASI), Gallipoli, 2015, pp. 141-145.

[4] M. A. Karri, "Thermoelectric power generation system optimization studies," ProQuest Diss. Theses, p. 124, 2011.

[5] G. J. Snyder, "Thermoelectric energy harvesting," in Energy Harvesting Technologies, 2009, pp. 325-336.

[6] D. Paul, "Thermoelectric energy Harvesting," ICT-Energy-Concepts Towards Zero-Power Information and Communication Technology, 2013.

[7] R. Bogue, "Energy harvesting and wireless sensors: A review of recent developments," Sens. Rev., vol. 29, no. 3, pp. 194-199, 2009.

[8] T. Ogawa, T. Ueno, T. Miyazaki and T. Itakura, "20 mV input, $4.2 \mathrm{~V}$ output boost converter with methodology of maximum output power for thermoelectric energy harvesting," 2016 IEEE Applied Power Electronics Conference and Exposition (APEC), Long Beach, CA, 2016, pp. 1907-1910.

[9] C. Veri, M. Pasca, S. D'Amico and L. Francioso, "A 40mV start up voltage DC-DC converter for thermoelectric energy harvesting applications," 2014 10th Conference on Ph.D. Research in Microelectronics and Electronics (PRIME), Grenoble, 2014, pp. 1-4.

[10] M. B. Machado, M. Sawan, M. C. Schneider and C. Galup-Montoro, "10 mV-1V step-up converter for energy harvesting applications," 2014 27th Symposium on Integrated Circuits and Systems Design (SBCCI), Aracaju, 2014, pp. 1-5.

[11] M. Alhawari, D. Kilani, B. Mohammad, H. Saleh and M. Ismail, "An efficient power management unit for $\mu$ Watt thermoelectric generators," 2015 International Conference on Information and Communication Technology Research (ICTRC), Abu Dhabi, 2015, pp. 148-151.

[12] Y. Teh and P. K. T. Mok, "Design consideration of recent advanced low-voltage CMOS boost converter for energy harvesting," 2015 European Conference on Circuit Theory and Design (ECCTD), Trondheim, 2015, pp. 1-4. 
[13] Y. C. Wong, A. R. Syafeeza, and N. A. Hamid, "A Transistor Sizing Tool for Optimization of Analog CMOS Circuits : TSOp," International Journal of Engineering and Technology (IJET). vol. 7, no. 1, pp. 140-146, 2015.

[14] M. Conti, P. Crippa, S. Orcioni, and C. Turchetti, "Layout-Based Statistical Modeling for the Prediction of the Matching Properties of MOS Transistors,"in IEEE Transactions on Circuits and Systems I: Fundamental Theory and Applications, vol. 49, no. 5, pp. 680-685, May 2002.

[15] J. Kyungsoo, L. Jinup, P. Jongmin, Y. Huikwan, C. Sanghyun, and C. Joongho, "A high efficiency CMOS DC-DC boost converter with current sensing feedback," Midwest Symp. Circuits Syst., vol. 2005, pp. 1661-1664, 2005.

[16] J. Wang, "Design of a Boost DC-DC Converter for Energy Harvesting Applications in 40nm CMOS Process," M.S. thesis, Delf University Of Technology, [Online]. Available:https://repository.tudelft.nl/islandora/object/ uuid:d86f720d-201e-4a34-a675b48a163aa5ee/datastream/OBJ/download, November, 2014.

[17] J. Goeppert and Y. Manoli, "Fully integrated start-up at $70 \mathrm{mV}$ of boost converters for thermoelectric energy harvesting," ESSCIRC Conference 2015 - 41st European Solid-State Circuits Conference (ESSCIRC), Graz, 2015, pp. 233-236.

[18] Z. Sun, K. W. R. Chew, H. Tang and L. Siek, "Adaptive Gate Switching Control for Discontinuous Conduction Mode DC-DC Converter," in IEEE Transactions on Power Electronics, vol. 29, no. 3, pp. 1311-1320, March 2014.

[19] Y. Zhang et al., "A Batteryless 19 \$ \mu\$W MICS/ISM-Band Energy Harvesting Body Sensor Node SoC for ExG Applications," in IEEE Journal of Solid-State Circuits, vol. 48, no. 1, pp. 199-213, Jan. 2013.

[20] M. Alhawari, B. Mohammad, H. Saleh and M. Ismail, "An all-digital, CMOS zero current switching circuit for thermal energy harvesting," 2015 European Conference on Circuit Theory and Design (ECCTD), Trondheim, 2015, pp. 1-4.

[21] E. J. Carlson, K. Strunz and B. P. Otis, "A $20 \mathrm{mV}$ Input Boost Converter With Efficient Digital Control for Thermoelectric Energy Harvesting," in IEEE Journal of Solid-State Circuits, vol. 45, no. 4, pp. 741-750, April 2010.

[22] H. Yu, M. Chen, C. Wu, K. Tang and G. Wang, "A Batteryless and Single-Inductor DC-DC Boost Converter for Thermoelectric Energy Harvesting Application with 190mV Cold-Start Voltage," 2018 IEEE International Symposium on Circuits and Systems (ISCAS), Florence, 2018, pp. 1-4.

[23] A. Das, Y. Gao and T. T. Kim, "A $76 \%$ efficiency boost converter with $220 \mathrm{mV}$ self-startup and $2 \mathrm{nW}$ quiescent power for high resistance thermo-electric energy harvesting," ESSCIRC Conference 2015-41 st European Solid-State Circuits Conference (ESSCIRC), Graz, 2015, pp. 237-240.

[24] A. N. F. Asli and Y. C. Wong, "-31 dBm sensitivity high efficiency rectifier for energy scavenging," AEU-Int. J. Electron. Commun., vol. 91, no. November 2017, pp. 44-54, 2018.

[25] Y. C. Wong, P. C. Tan, M. M. Ibrahim, A. R. Syafeeza, and N. A. Hamid, "Dickson Charge Pump Rectifier using Ultra-Low Power ( ULP ) Diode for BAN Applications," J. Telecommun. Electron. Comput. Eng., vol. 8, no. 9, pp. 77-82, 2016.

\section{BIOGRAPHIES OF AUTHORS}

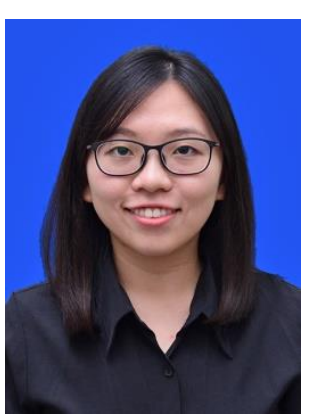

Jim Hui Yap received the B.Eng. degree in Electronics from Universiti Teknikal Malaysia Melaka in 2018. She is currently pursuing the M. Sc. Degree at the Faculty of Electronics and Computer Engineering, Universiti Teknikal Malaysia Melaka (UTeM), Malaysia. Her research interests include CMOS voltage booster and low power application.

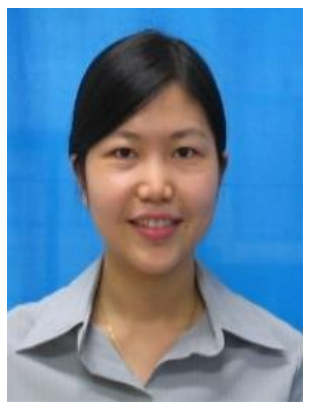

Yan Chiew Wong received her doctorate from The University of Edinburgh, United Kingdom on 2014.She is currently a senior lecturer in Universiti Teknikal Malaysia Melaka. She has more than 5 years industry experience in semiconductor process design in Infineon Technologies and Intel. Her research field involving of RF and mixed signal circuitries, adaptive impedance matching and power management control system. She also produced a number of research papers in the field of adaptive algorithm, RF reconfigurable design, EDA and etc. She has been successfully design and develop high voltage CMOS control chips and RF circuitries. 